\title{
Improvement of Systemic Symptoms after Dental Implant Removal
}

\author{
Yoshiro Fujii \\ Shin Kobe Dental Clinic, Kobe City, Japan \\ Email: shin-kobe-dentalclinic@s9.dion.ne.jp
}

Received 28 December 2015; accepted 16 February 2016; published 19 February 2016

Copyright (C) 2016 by author and Scientific Research Publishing Inc.

This work is licensed under the Creative Commons Attribution International License (CC BY). http://creativecommons.org/licenses/by/4.0/

c) (i) Open Access

\begin{abstract}
Dental implants have spread worldwide in dentistry. The risks and complications reported are limited to local issues. However, in this case, a patient complained of systemic symptoms after dental implantation. This case report aims to demonstrate that systemic symptoms such as lumbago, shoulder stiffness, neck pain, hip joint pain, and facial pain improved after the removal of wellosseointegrated titanium implants. The results suggest that harmful electromagnetic waves received by implants affect body conditions; however, to date, the underlying mechanisms have not been identified. Therefore, further research is required.
\end{abstract}

\section{Keywords}

Dental Implant, Electromagnetic Waves, Titanium Implant, Systemic Symptoms

\section{Introduction}

A dental implant is a surgical structure that interfaces with the jaw or skull bone to support a dental prosthesis such as a crown, bridge or removable denture. It replaces a tooth root. It provides a strong foundation for a fixed or removable replacement artificial tooth that is made to match a natural tooth. There are many advantages to a dental implant, including: improved appearance, improved speech, improved comfort, easier eating, etc. compared to other dental prosthesis such as a bridge, or denture. A dental implant is a cylindrical and/or tapered post, which serves as a substitute for the tooth root. Normally, a special device (the abutment) is attached to the implant. The abutment will hold the dental prosthesis. Recently, titanium and titanium alloys are commonly used as dental implant materials. The process of integration of titanium with bone has been termed as "osseointegration" by Branemark [1]. Risks and complications associated with implant therapy have been divided into those that occur during surgery (including infection at the implant site; injury or damage to surrounding structures such as other teeth or blood vessels; nerve damage, which can cause pain, numbness, or tingling in natural teeth, 
gums, lips or chin; and sinus problems when dental implant(s) placed in the upper jaw protrude into the sinus cavity) [2]; in the first 6 months (including infection and failure to osseointegrate); and over the long term (including peri-implantitis and mechanical failure) [3]. In the presence of healthy tissues, a well-osseointegrated implant with appropriate biomechanical loads can have long-term success rates of $93 \%$ - 98\% for the fixture [4]-[6] and a lifespan of 10 - 15 years for the prosthetic teeth [7]. However, although the implant is well osseointegrated, it may receive harmful electromagnetic waves, resulting in many adverse systemic conditions [8] [9]. This study presents a case in which many affected body conditions improved after the removal of two implants.

\section{Case Report}

\section{Subject and Methods}

The subject was a woman in her 50s who developed pain in her back, hip joints, neck, face, and legs as well as shoulder stiffness after a titanium dental implantation in the space left by the removal of her upper right molars. Manual body therapy such as chiropractic therapy was effective temporarily. She had an operation in which two titanium implants were installed around 8 years ago. The topical conditions around the implants after the operation were good. There were two titanium dental implants but no over-structures installed yet (Figure 1 and Figure 2) because of her serious systemic conditions, although there were no topical conditions around the implants, including peri-implantitis (Figure 1). The implants appeared well-osseointegrated with the alveolar bone (Figure 2).

When an active cell phone was brought close to the left side of her head while she was standing, her body showed no change. However, when it was brought close to the right side of her head, she leaned towards the cell phone (Figure 3).

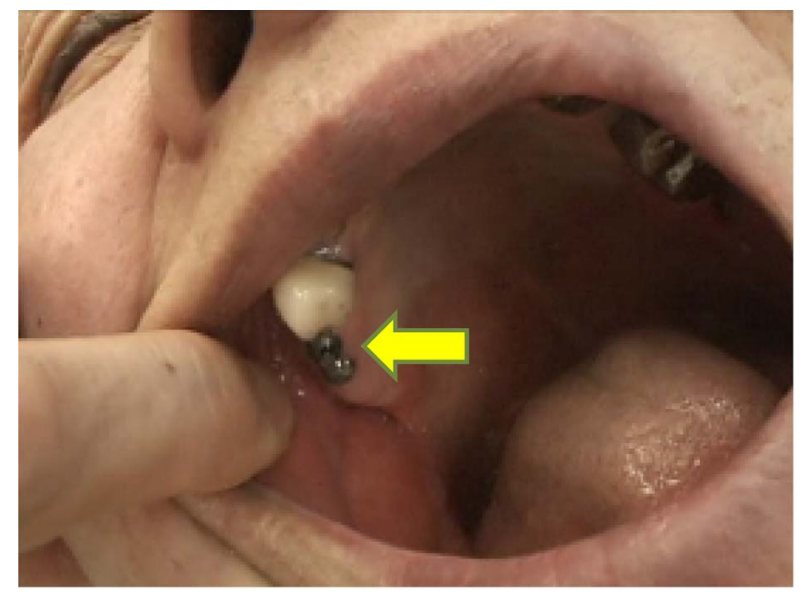

Figure 1. There were two titanium dental implants in the space left after the extraction of her upper right molars without over structures (arrow). There were no topical conditions around them.

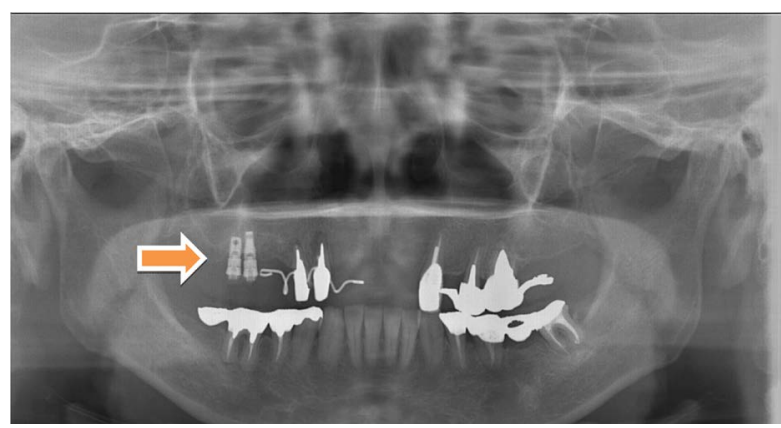

Figure 2. A panoramic X-ray image of the two titanium dental implants in the space left by her upper right molars (arrow). 
When the left straight leg raising (SLR) test was performed, her left leg could be lifted to an angle of only approximately $80^{\circ}$ and she felt tension and pain around her left hip joint (Figure 4) when her right leg was lifted to an angle of approximately $90^{\circ}$. The abduction of her left hip joint was limited by pain and tension; therefore, her left knee could not touch the bed (Figure 5) whereas her right knee could.

When the implants were covered with aluminum foil (Figure 6), her left leg could be lifted to an angle of approximately $90^{\circ}$ in the SLR test (Figure 7) and her left hip joint movement also improved (Figure 8).

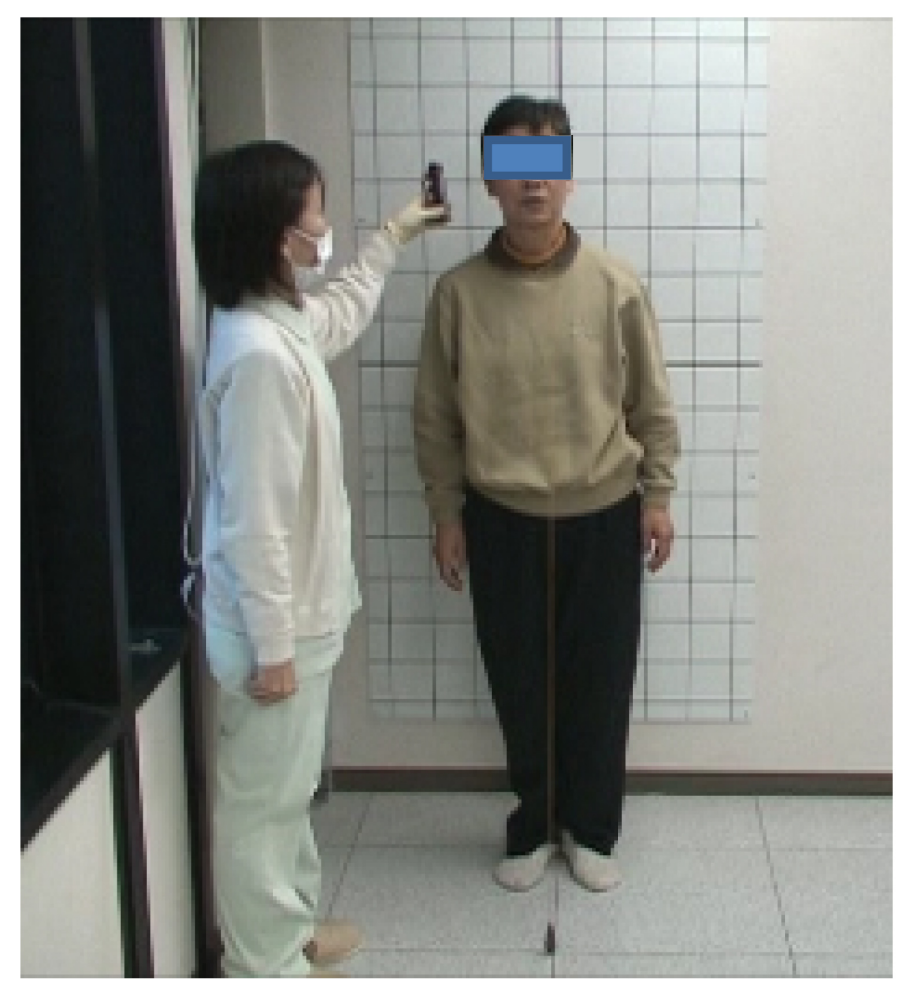

Figure 3. When an active cell phone was brought close to the right side of her head while she was standing, her body leaned towards the cell phone.

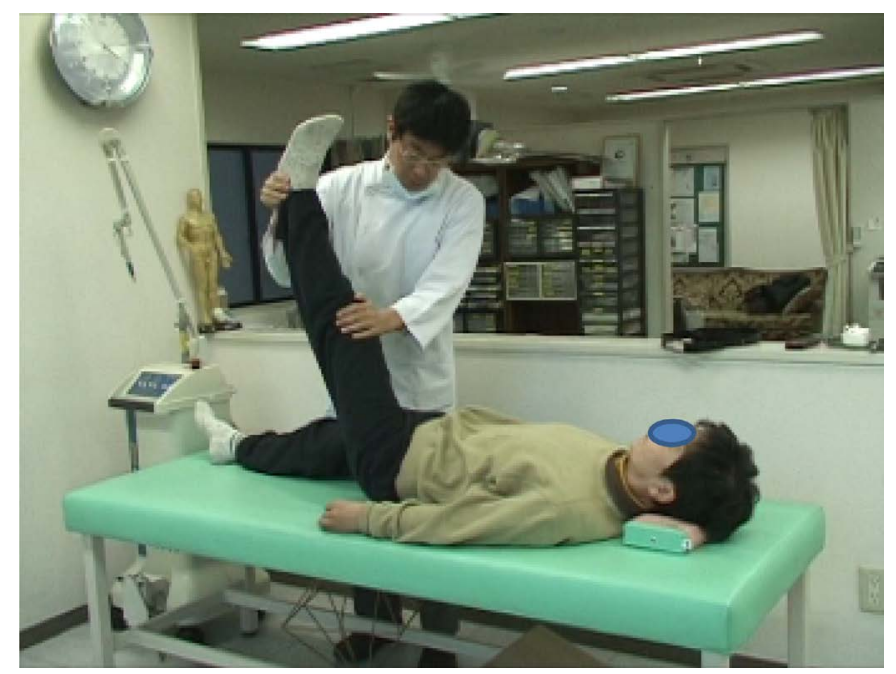

Figure 4. The patient's left leg could be lifted to an angle of only approximately $80^{\circ}$ owing to pain and tension in the straight leg raising (SLR) test, whereas her right leg could be lifted to $90^{\circ}$. 


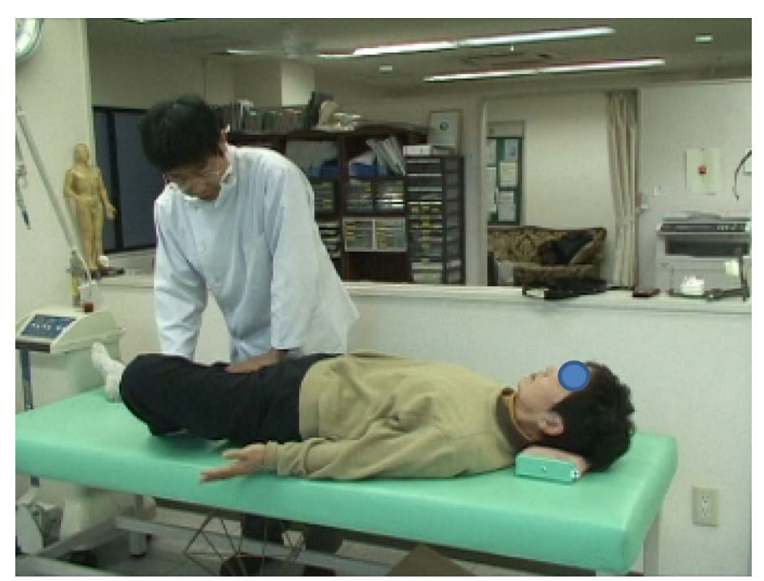

Figure 5. The patient's left hip joint abduction was limited by pain and tension; therefore, her left knee could not touch the bed whereas her right knee could.

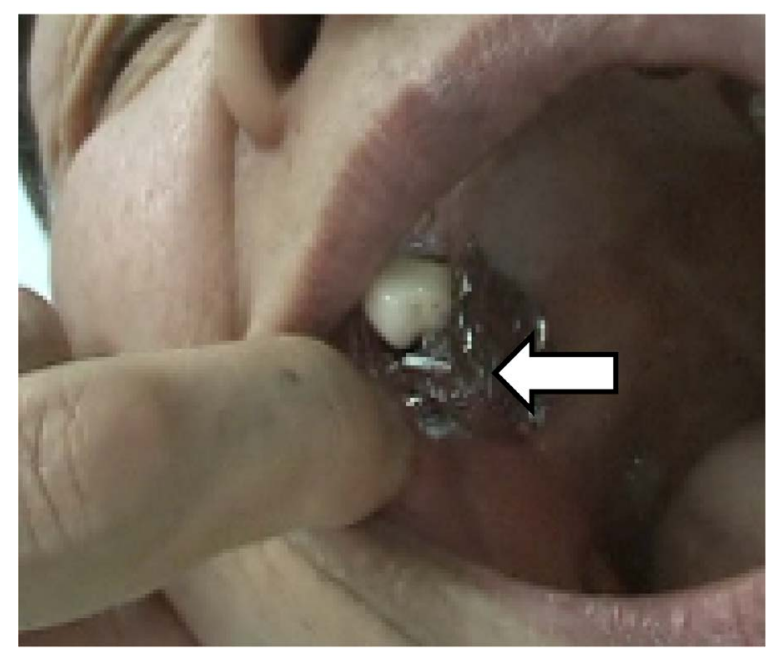

Figure 6. The implants were covered with aluminum foil (arrow).

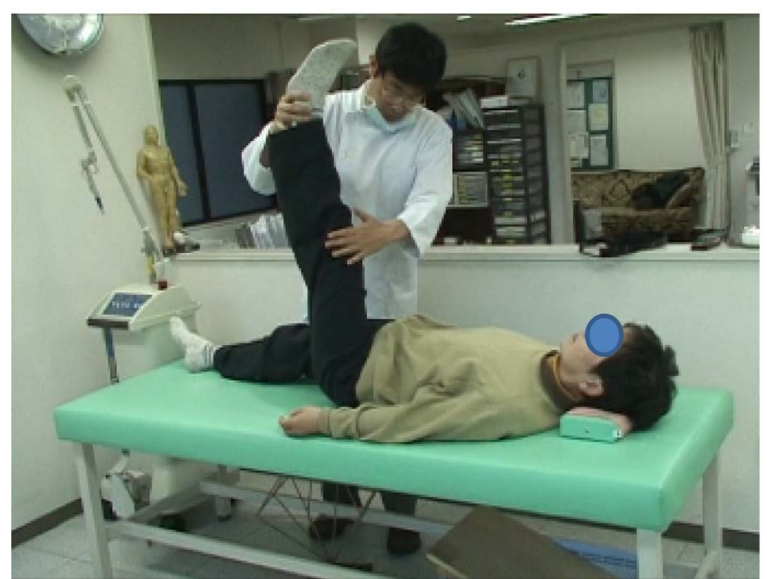

Figure 7. The patient's left leg was lifted to an angle of approximately $90^{\circ}$ in the SLR test performed after covering the implants with aluminum foil. 
The implants were removed by an oral surgeon (Figure 9). After the removal, her left SLR and hip joint rotation improved. Her left leg could be raised to an angle of more than $90^{\circ}$ in the SLR test after the removal of implants (Figure 10). Her left hip joint rotation also improved; therefore, her left knee could easily touch the bed.

All the systemic symptoms from which the patient was suffering also improved. However, when the removed implants (Figure 11) were placed on her chest (Figure 12), her left SLR and hip joint rotation decreased again owing to tension and pain (Figure 13). As soon as the implants were removed from her chest, her left hip abduction rotation increased. Moreover, when an active cell phone was brought close to her while she was standing, her body no longer leaned (Figure 14). However, after the implants were attached to her body, when an active cell phone was brought close to her right side, her body leaned toward it (Figure 15).

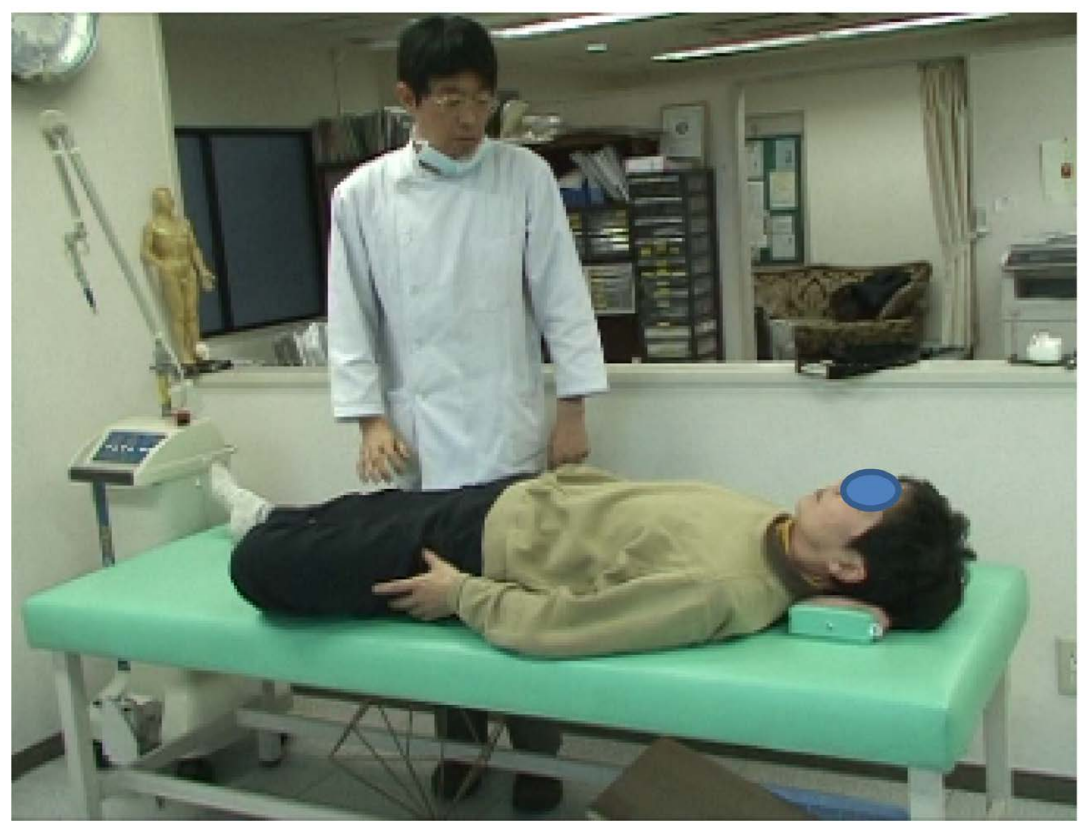

Figure 8. When the implants were covered with aluminum foil, the patient's left hip joint abduction also improved; and, her left knee could touch the bed.

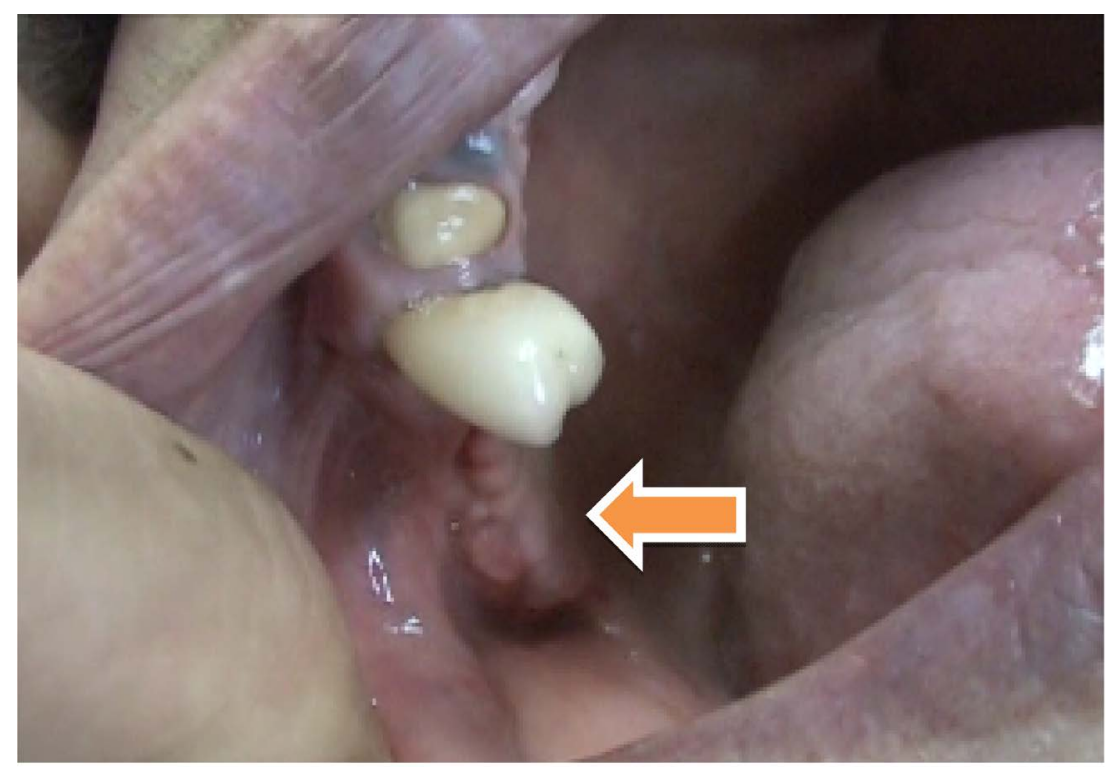

Figure 9. The implants were removed from the subject's right upper jaw. See Figure 1 for comparison (arrow). 


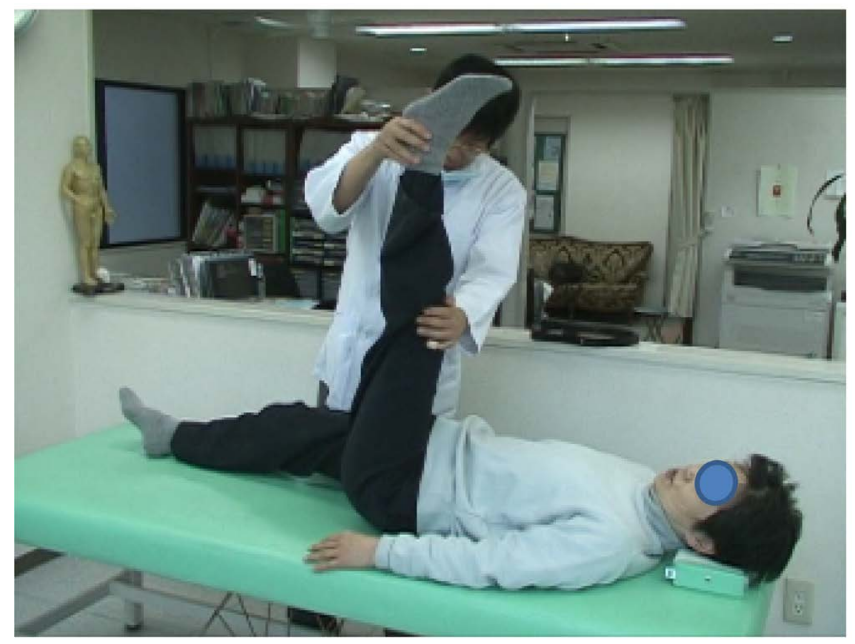

Figure 10. Her left leg was raised to an angle of more than $90^{\circ}$ in the SLR test performed after the removal of implants.

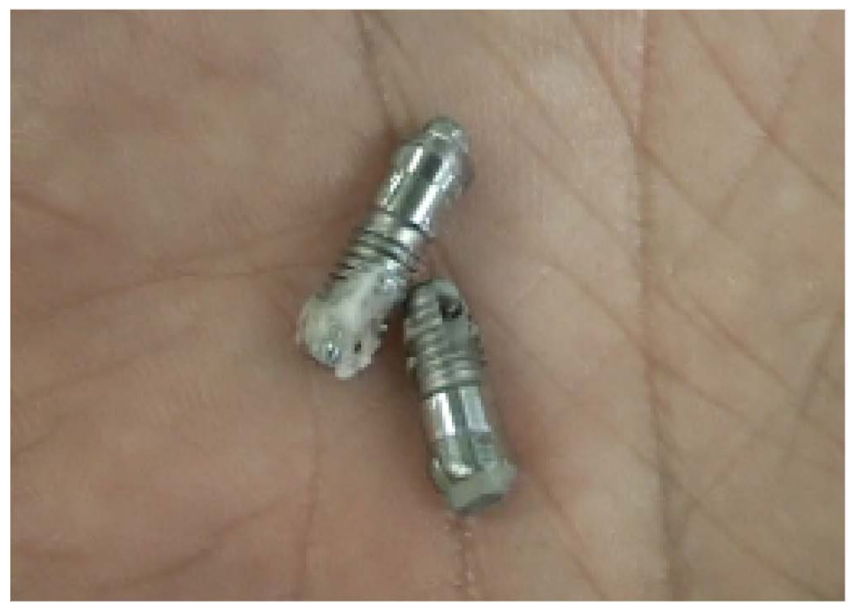

Figure 11. The two titanium implants that were removed.

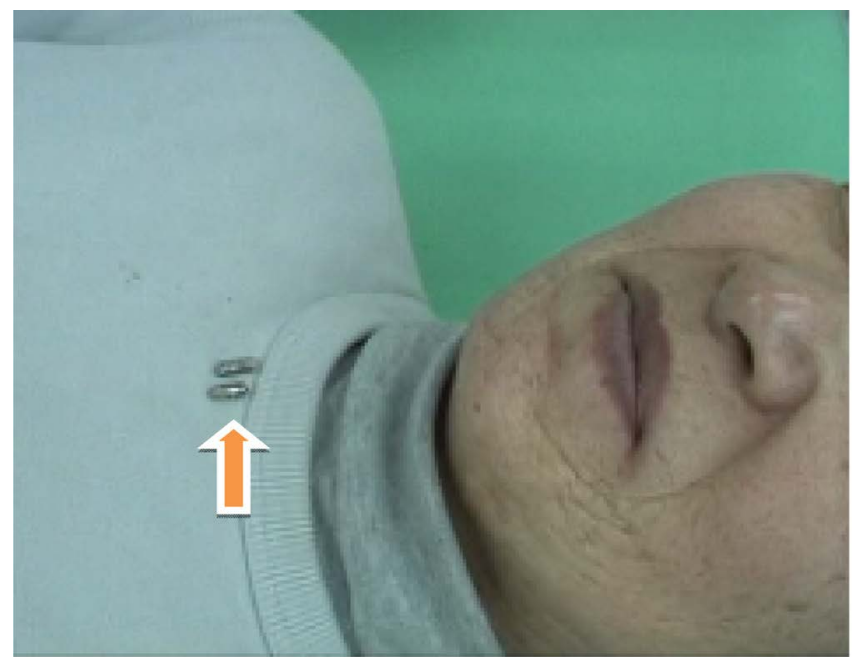

Figure 12. The removed implants were placed on the subject's chest (arrow). 


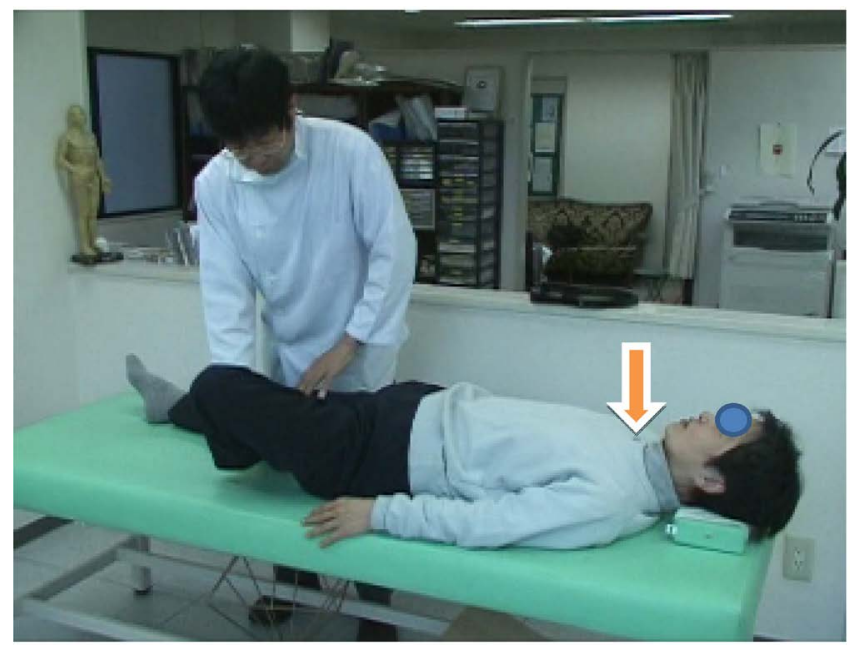

Figure 13. When the implants were placed on the patient's chest (arrow), her left SLR and hip joint outer rotation decreased. As soon as the implants were removed, her joint movement returned.

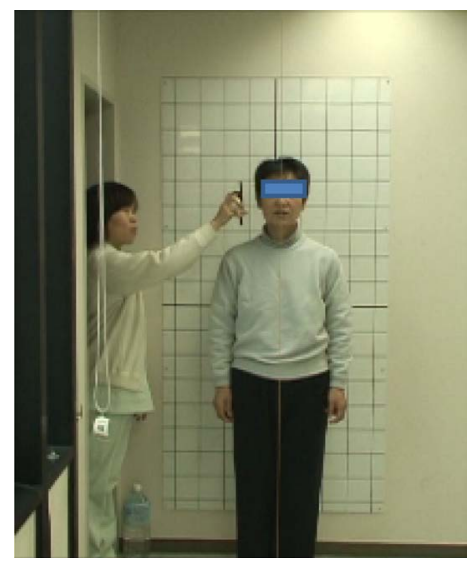

Figure 14. When an active cell phone was brought close to the right side of the patient's head while she was standing, her body no longer leaned.

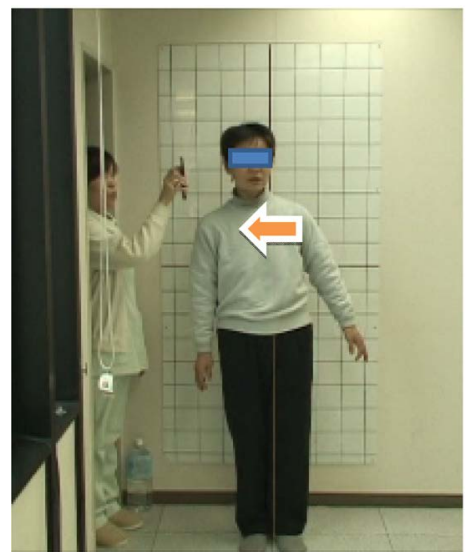

Figure 15. When an active cell phone was brought close to the right side of the patient's head, her body leaned towards the cell phone after the attachment of the implants to her body (arrow). 
The dentist constructed a partial denture containing a gold and platinum alloy as a prosthesis to compensate for the missing teeth. Dental materials used for construction of the denture were determined using the Bi-Digital O-Ring Test [10] [11]. After this treatment, her body condition improved markedly and her prognosis was good. No side effects were shown. The symptoms described above did not recur.

The experiment conducted in this case can be observed in a YouTube video, "Hip joint pain, back pain and shoulder stiffness after implantation of dental implants" (https://www.youtube.com/watch?v=b8sqdxsuLyA; last accessed 12/18/2015).

\section{Discussion}

The author has previously reported a case in which dizziness and joint mobility disorder were induced by harmful electromagnetic waves collected by a dental onlay [12] and a case in which balance dysregulation and dizziness were induced by harmful electromagnetic waves collected by a dental amalgam filling [13]. The author has also reported cases in which dental implants may collect harmful electromagnetic waves [8] [9] [14]. In the present case, the two titanium implants may have collected harmful electromagnetic waves, resulting in many systemic conditions and balance dysregulation. In the present case, when the active cell phone was brought close to her right side, her body leaned towards the cell phone before treatment. After the attachment of the implants to her body, when the active cell phone was brought close to her right side, her body leaned towards the cell phone, although the impacts were removed. The author observed some patterns of balance dysregulation when an active cell phone was brought close to the subject, i.e., the subject leaned away from the cell phone (Figure 16) and the subject's body moved to the right and left [15] (Figure 17(a) and Figure 17(b)).

Because the mechanism underlying this balance dysregulation is unclear, more research is needed. However, one of the mechanisms may be the effect on cerebral blood flow [16].

Aluminum foil is useful for temporarily interfering with electromagnetic waves, allowing diagnosis of adverse conditions caused by harmful electromagnetic waves [9] [12] [13] [15]. In the present case, it may have interfered with absorption of electromagnetic waves by the implants. However, aluminum foil covering is not a practical solution because it cannot be indefinitely applied. The best option for treating the root cause of the problem appeared to be the surgical removal of implants. Following the surgery, all symptoms improved, but

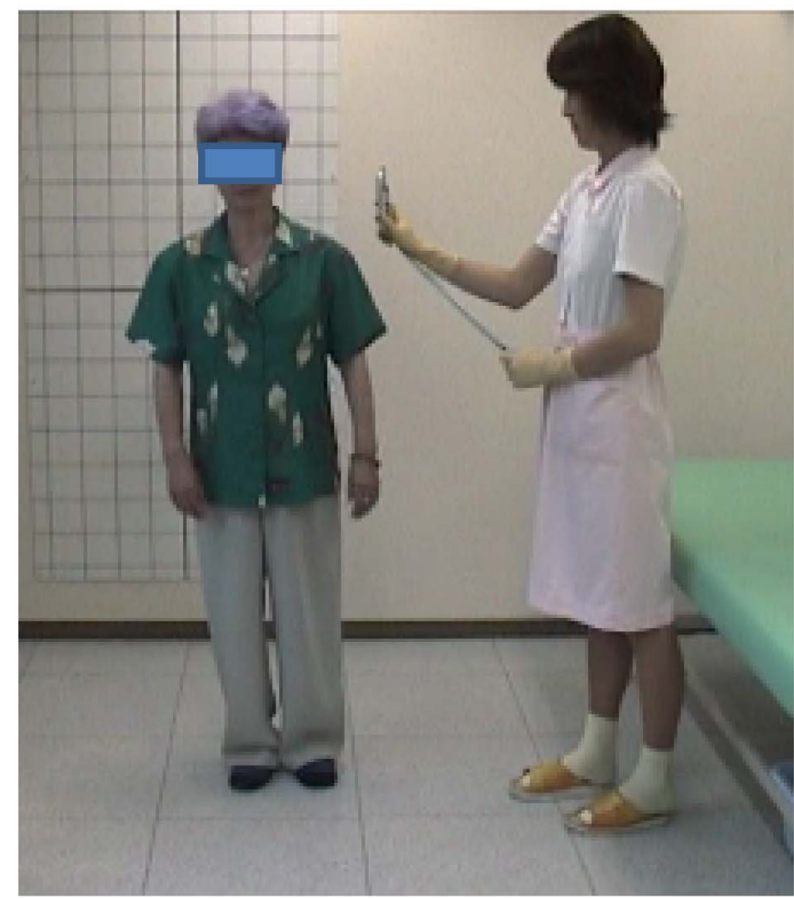

Figure 16. A pattern example of balance dysregulation, wherein the subject leaned away from the cell phone when an active cell phone was brought close to the subject. 


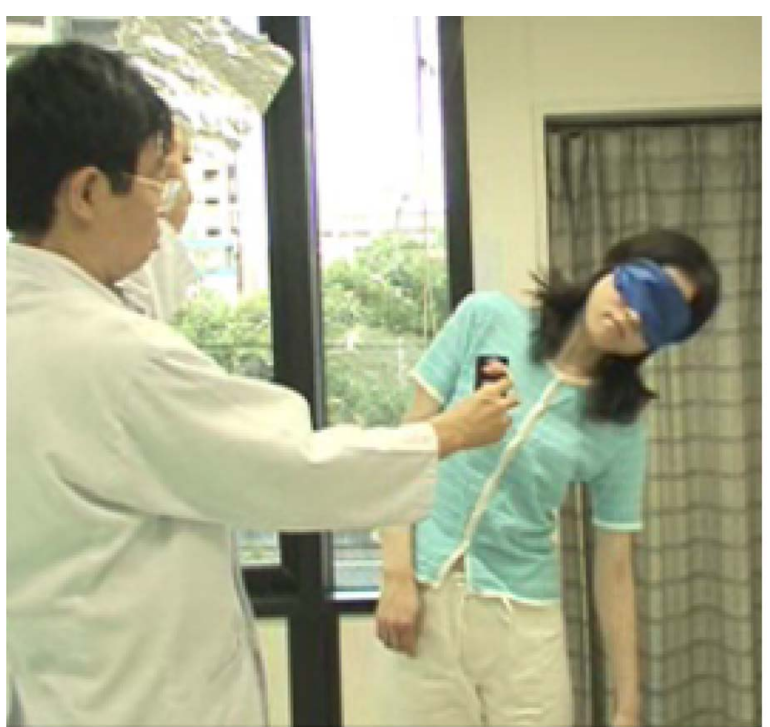

(a)

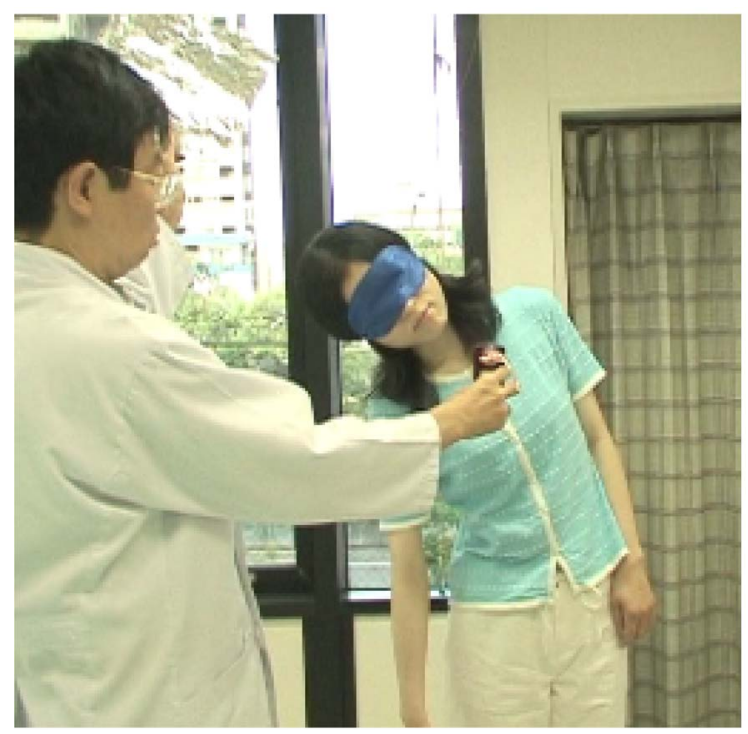

(b)

Figure 17. A pattern example of balance dysregulation, wherein the subject's body moved right and left when an active cell phone was brought close to the subject.

some reoccurred when the removed implants were placed on her chest. The dentist made a partial denture to restore her biting condition. Her symptoms did not recur after the denture was installed and prognosis was good. No side effects occurred. The dentist instructed the patient not to keep on or near her body any substances that collect harmful electromagnetic waves after the completion of the dental treatment to prevent recurrence. Owing to the severity of the possible adverse effects, it is important to confirm that no negative side effects are present before surgical procedures are performed. If joint mobility decreases when implants are attached to the patient [12], the dental implant procedure should be avoided. Moreover, if balance dysregulation [9] [12], scoliosis [8], or involuntary body movement [15] present when implants are attached to a patient during irradiation with electromagnetic waves emitted by a cell phone, the dental implant procedures should be avoided.

\section{Conclusion}

Dental implants have spread worldwide in dentistry. The risks and complications reported are limited to local complaints. However, some patients may complain of systemic symptoms after installation of dental implants. This case report showed that many systemic symptoms such as lumbago, shoulder stiffness, neck pain, hip joint pain, and facial pain improved after the removal of well-osseointegrated titanium implants. The results suggest that harmful electromagnetic waves collected by the implants may affect body conditions. Accordingly, testing for the adverse effects of electromagnetic waves is needed before dental implant surgery. Further research with multidisciplinary cooperation may shed light on the underlying mechanisms.

\section{References}

[1] Branemark, P.I., Hansson, B.O., Adell, R., Breine, U., Lindstrom, J., Halloeno, O., et al. (1997) Osseointegratedim Plants in the Treatment of the Edentulous Jaw: Experience from a 10 Year Period. Scandinavian Journal of Plastic and Reconstructive Surgery and Hand Surgery. Supplementum, 16, 1-132.

[2] http://www.mayoclinic.org/tests-procedures/dental-implant-surgery/basics/risks/prc-20009052

[3] Esposio, M., Hirsch, J.M., Lekholm, U. and Thomsen, P. (1998) Biological Factors Contributing to Failures of Osseointegrated Oral Implants. (II). Etiopathogenesis. European Journal of Oral Sciences, 106, 721-764. http://dx.doi.org/10.1046/j.0909-8836..t01-6-.x

[4] Papaspyridakos, P., Mokti, M., Chen, C.J., Benic, G.I., Gallucci, G.O. and Chronopoulos, V. (2013) Implantand Prosthodontic Survival Rates with Implant Fixed Complete Dental Prostheses in the Edentulous Mandible after at Least 5 Years: A Systematic Review. Clinical Implant Dentistry and Related Research, 11, 705-717.

[5] Berglundh, T., Persson, L. and Klinge, B. (2002) A Systematic Review of the Incidence of Biological and Technical 
Complications in Implant Dentistry Reported in Prospective Longitudinal Studies of at Least 5 Years. Journal of Clinical Periodontology, 29, 197-212. http://dx.doi.org/10.1034/j.1600-051X.29.s3.12.x

[6] Pjetursson, B.E., Thoma, D., Jung, R., Zwahlen, M. and Zembic, A. (2012) A Systematic Review of the Survival and Complication Rates of Implant-Supported Fixed Dental Prostheses (FDPs) after a Mean Observation Period of at Least 5 Years. Clinical Oral Implants Research, 23, 22-38. http://dx.doi.org/10.1111/j.1600-0501.2012.02546.X

[7] Bozini, T., Petridis, H., Garefis, K. and Garefis, P. (2011) A Meta-Analysis of Prosthodontic Complication Rates of Implant-Supported Fixed Dental Prostheses in Edentulous Patients after an Observation Period of at Least 5 Years. The International Journal of Oral \& Maxillofacial Implants, 26, 304-318.

[8] Fujii, Y. (2012) Do Dental Implants Cause Scoliosis? Case Report. Personalized Medicine Universe, 1, 79-80. http://dx.doi.org/10.1016/j.pmu.2012.05.012

[9] Fujii, Y. (2014) Sensation of Balance Dysregulation Caused/Aggravated by a Collection of Electromagnetic Waves in a Dental Implant. Open Journal of Antennas and Propagation, 2, 29-35. http://dx.doi.org/10.4236/ojapr.2014.23004

[10] Omura, Y. (1993) Bi-Digital O-Ring Test for Imaging and Diagnosis of Internal Organs of a Patient. US Patent 5188107. http://academic.reed.edu/economics/parker/f11/354/pat/o-ring.pdf

[11] http://bdort.org/

[12] Fujii, Y. (2015) Dental Treatment for Dizziness and Joint Mobility Disorder Caused by Harmful Electromagnetic Waves. Open Journal of Antennas and Propagation, 3, 1-7. http://dx.doi.org/10.4236/ojapr.2015.31001

[13] Fujii, Y. (2015) Electromagnetic Waves Collected by a Dental Amalgam Filling Induced Balance Dysregulation and Dizziness over a Period Exceeding 10 Years. Open Journal of Stomatology, 5, 235-242. http://dx.doi.org/10.4236/ojst.2015.510029

[14] Fujii, Y. (2014) Sense of Balance Disorder Caused by Electromagnetic Waves Collected by a Dental Implant. Acupuncture and Electro-Therapeutics Research, 39, 379.

[15] Fujii, Y. (2014) Gold Alloy Dental Inlay for Preventing Involuntary Body Movements Caused by Electromagnetic Waves Emitted by a Cell Phone. Open Journal of Antennas and Propagation, 2, 37-43. http://dx.doi.org/10.4236/ojapr.2014.24005

[16] Aalto, S., Haarala, C., Brück, A., Sipilä, H., Hämäläinen, H. and Rinne, J.O. (2006) Mobile Phone Affects Cerebral Blood Flow in Humans. Journal of Cerebral Blood Flow and Metabolism, 26, 885-900. http://dx.doi.org/10.1038/sj.jcbfm.9600279

\section{Additional Information}

Informed consent for publication was obtained from the subject.

SLR: Straight Leg Raise (SLR) test is one of the neurodynamic tests. The neurodynamic tests check the mechanical movement of the neurological tissues as well as their sensitivity to mechanical stress or compression. These tests along with relevant history and decreased range of motion, are considered by some to be the most important physical signs of disc herniation, regardless of the degree of disc injury. SLR is such a neural tension test that can be used to rule out neural tissue involvement as a result of a space occupying lesion, often a lumbar disc herniation. It is one of the most common neurological tests of the lower limb. It is a Passive test, and each leg is tested individually with the normal leg being tested first. When performing the Straight Leg Raise test, the patient is positioned supine without pillows, the hip medially rotated and adducted and the knee extended. The clinician lifts the patient's leg by the posterior ankle while keeping the knee in a fully extended position. The clinician continues to lift the patient's leg by flexing at the hip until the patient complains of pain or tightness in the back or back of the leg.

Cited from http://www.physio-pedia.com/Straight_Leg_Raise_Test. 